\title{
Precision in Physiotherapy
}

\author{
JAMES CYRIAX, M.D., M.R.C.P., \\ Physician to the Department of Physical Medicine, St. Thomas' Hospital, London.
}

Physiotherapy evolved at a time when doctors had not yet learned how to make accurate diagnoses in soft-tissue disorders. Vague concepts had led to vague treatments, and no one was ashamed to prescribe or to administer for example, heat, diffuse massage or general exercises. Now, of course, this sort of physiotherapy is rightly regarded with increasing scepticism, and is being replaced by methods directly influencing the lesion itself. All pain arises from a lesion, and it is axiomatic that all treatment must reach the lesion and exert a beneficial effect on it. Referred pain may mean that the point on which treatment must be concentrated lies outside the area of pain; the lesion may well not even be found tender. This does not matter if the physiotherapist brings her anatomical knowledge and pair of skilled hands to bear on the problem, for, supplied with an accurate diagnosis, she can nowadays give treatment of great precision. She can thus afford immediate and lasting benefit in disorders in which it had previously been thought that physiotherapy had nothing to offer, and indeed that no effective treatment existed.

The essentials are therefore an accurate diagnosis and a physiotherapist who knows how to use her hands with precision. The former is supplied by the doctor, but the physiotherapist should understand his methods, since she uses the same examination for the assessment of progress. The latter can be taught to the physiotherpist, provided that she understands the phenomena of referred pain, and is prepared to base her treatment on applied anatomy rather than a search for tenderness. Unfortunately, for decades it had been regarded as enough, in the diagnosis of softtissue lesions, to palpate the painful area in search of a localized tender area-the so-called nodule of "fibrositis". This misleading notion has led to endless treatment to the wrong spot; it is based on inadequate clinical examination of patients and ignores the fact that wherever there is referred pain there is apt to be referred tenderness too. Indeed, the position of the tender point can be just as misleading as that of the pain; both may well be referred. Nothing, therefore, is to be gained by indiscriminate palpation of a painful area. The ordinary medical principles that apply to the examination of all tissues must be followed -namely, the assessment of function. This happens to be easy in the case of the moving parts, since each tissue works in a characteristic way.

The primary function of the moving parts is for the bones to move at the joints, and the muscles, activated by nervous impulses, to move them. The object of clinical examination is thus. to determine, firstly, about what joint the lesion lies, and, secondly, whether an inert or a contractile tissue is involved. Once these two major points are decided, accessory tests must be used in an attempt to narrow the diagnosis down to a single spot.

\section{Selective Tension}

Tension brings on or aggravates pain in lesions of the moving parts. Diagnosis depends on the assessment of function and is therefore approached indirectly by applying selective tension to each of the moving tissues in turn. From these responses a pattern emerges that identifies precisely the tissue at fault. Search for tenderness is avoided so far as is possible, but, if it proves necessary, if it is confined to the structure already identified by this study of function as containing the lesion. When a number of movements are tested, some are found to be painful, weak or limited, others normal. The negative side of the examination is as important as the positive, since, if one movement indicates that a lesion lies in a certain position, it follows that all movements that do not affect that part of that tissue must be of full range, painless and strong. Hence interpretation is based on the pattern-that is, congruous positive findings at one point balanced by negative findings elsewhere.

The main distinction when the moving parts are examined is between the contractile structures (muscle and tendon) and the inert structures (capsule, ligament, bursa, dura mater, nerve-root or nerve-trunk). Strong, resisted contraction with the joint held still applies tension on muscle and tendon only; stretching in the opposite direction may hurt too. Pain arising from inert structures appears on stretching only.

\section{EXAMINATION OF FUNCTION}

\section{Six different sets of data are correlated, as follows:}

\section{Active movements}

These give a combined indication of the range of movement, muscle power, and state of voluntary control. Since range and power are assessed separately later, their chief virtue is to indicate willingness. Marked discrepancy between on the one hand the range of active movement, and on the other hand either the range attained passively or muscular strength, indicates a psychogenic disorder.

\section{Passive movements}

These indicate the state of the inert structures without introducing complications due to muscle power and willingness.

Capsular pattern: If the entire fibrous cuff about any joint is found contracted, arthritis is present. The limitation of movement found corresponds to the capsular pattern, This is different for different joints, but maintains constant proportions at any one joint. For example in arthritis at the shoulder, if abduction is say 45 degrees limited, lateral rotation will be 60 degrees limited but medical rotation only 15 degrees limited.

Non-capsular pattern: If the known proportions are not found, ligamentous sprain, internal derangement, bursitis, neoplasm, contractures of an extra-articular structure, or hysteria is present.

\section{Resisted movements}

One movement is tested for each group of muscles. The patient contracts the muscle with all his strength while the examiner applies such a degree of resistance that the joint itself does not move. The state of each muscle is thus assessed in isolation. If a full and painless range of passive movement exists at the relevant joint and only one resisted movement hurts, a muscle lesion is present. If several contradictory resisted movements hurt, the muscles are unaffected. Painless muscle weakness without increase of pain characterises complete rupture or a neurological condition. A tendonous lesion cannot give rise to limitation of passive movement.

\section{Painful are}

If a tender structure lies between two bony surfaces it can be painfully squeezed when they are approximated, A painful arc results-that is, pain at the mid-range of a movement, disappearing as the extremes are approached. For example, in supraspinatus and infraspinatus tendinitis and in subdeltoid bursitis, the lesion lies between the acromion and the greater tuberosity of the humerus. There- 


\title{
TEXT-BOOK OF ORTHOPAEDIC MEDICINE
}

\author{
by JAMES CYRIAX, M.D., M.R.C.P.
}

\author{
Physician to the Department of Physical Medicine, St. Thomas's Hospital, London
}

\section{VOLUME ONE \\ DIAGNOSIS OF SOFT TISSUE LESIONS \\ FOURTH EDITION}

VOLUME TWO

TREATMENT BY

DMANIPULATION

AND MASSAGE

SIXTH EDITION
Disorders of the moving parts present special diagnostic problems. In this work Dr. Cyriax deals with the multiplicity of soft tissue lesions likely to be found in each region of the body and describes a system of clinical examination whereby the source of a pain can be precisely located-an essential preliminary to accurate treatment.

735 pp. Demy 8vo, 135 line drawings, 40 half-tone plates, R6.40

An indispensable textbook for the practising physiotherapist. The basic principles of manipulation and massage are carefully considered, as are indications for and against treatment. The manual methods advocated are those practised at St. Thomas's Hospital, each technique being clearly described and illustrated with a full half-tone plate. The place of traction is emphasized and there are useful chapters on local injection of hydrocortisone, massage in plastic surgery and friction for varicose ulcers-

"This textbook has greatly impressed me and I would advocate that every practising physiotherapist should read it."

-British Journal of Physiotherapy

\section{CASSELL MEDICAL BOOKS \\ HEINEMANN \& CASSELL (S.A.) (PTY.) LTD.}

\author{
P.O. Box 275 Cape Town - P.O. Box 1190, Johannesburg
}

fore, tenderness of any of these three structures may give rise to a painful arc. In the case of the tendons, the arc is associated with pain on resisted abduction and lateral rotation respectively. If the bursa is at fault neither of these resisted movements hurts. Since the simplest anatomical considerations indicate clearly where the tissue, since it lies in a pinchable position, must lie, an arc is a valuable localising sign.

\section{Pain at one extreme}

This may be produced by squeezing or by stretching one structure. Accessory tests serve to show which of these alternatives obtains.

\section{Palpation}

This may reveal warmth; if so, this fact indicates activity. Activity is found in: recent injury or operation, fracture, internal derangement, neoplasm eroding bone, blood in the joint, rheumatoid or gouty arthritis, and bacterial infection. Fluctuation indicates fluid, which may be clear effusion or blood. Synovial thickening, crepitus, loose bodies, cysts, osteophytes and bony enlargement are detectable by palpation. Tenderness serves to indicate the exact site of a lesion only if palpation is confined to the tissue already singled out by study or the diagnostic movements as that affected, and can be carried out only if the tissue at fault lies within reach of the examiner's finger. In, say a disc-lesion, palpation of muscle or spinous processes for tenderness is quite pointless, for the lesion is entirely out of reach.

\section{CONFIRMATION}

Radiography seldom clarifies a diagnosis in lesions of the soft tissues and may prove most misleading, a minor osseous deviation from the normal being regarded as relevant when clinical examination would have shown some quite other disorder to be present. Only when the radiographic appearances coincide with the clinical diagnosis should they be given full weight, unless an over-riding disease is unexpectedly disclosed. Local analgesia provides the only means of disproving or confirming a localization arrived at clinically, and in all cases of doubt should be induced at once. After the injection whatever movement had been found painful is tested again.

\section{PSYCHOGENIC PAIN}

Patients with pain for which no objective signs are found to account are normally sent for diagnosis to a department of physical medicine. Amongst the many with pains in the trunk or limbs there are sure to be some whose trouble is in fact emotional. They set up suspicion by a garbled history and, on clincal exmination, identify themselves at once by the number of inconsistencies that they offer. The neat pattern that the patient with an organic lesion presents is replaced by a series of self-contradictory allegations. It is not the absence of physical signs that enables a confident diagnosis of neurosis to be made; it is the evidence afforded by mutually inconsistent findings. The system of diagnosis outlined above can alone ensure that the relevant facts emerge.

\section{TREATMENT}

Physiotherapy is largely concerned with the maintenance or restoration of painless mobility. There are three ways of achieving this effect:

1. Exercises (well-taught to all physiotherapy students);

2. Deep massage;

3. Manipulation.

Deep massage results in a localized movement imparted to a tissue by the physiotherapist's finger. It exerts its effect over a small area, and is all the more effective for such con- 
centration; but it has no effect, say, half-an-inch away. Deep massage mobilizes the tissues only at the point of treatment and must therefore be administered with great accuracy. Manipulation also stretches or moves tissues, but like deep massage is suited to only some types of disorder. Moreover, proper understanding of the nature and position of the lesion alone enables the physiotherpist to vary her manipulative technique to suit separate disorders and patients with different degrees of sensitiveness.

The employment of these manual techniques brings a number of common lesions, hitherto intractable, within the scope of physiotherapy. It carries the added advantage that the situation no longer persists whereby the patient, after months of vain physiotherapy, finds relief at the hands of a lay manipulator. This is a ridiculous situation; any patient curable by manipulation should never have been forced to go outside our two professions, but should have received this treatment within the medical sphere as a matter of course. Proper diagnosis followed by prompt and effective treatment also avoids the alternative evil of endless lay manipulation in patients who cannot be benefited by this means.

\section{ENVOY}

Accurate manual techniques, based on an exact diagnosis, have been the theme of Miss Hickling's lectures to you during the spring of this year. I hope that you will appreciate and remember her teaching and employ our methods with the precision that they deserve, taking equal trouble over the diagnosis as with the manual technique, and avoiding these methods in unsuitable cases as assiduously as you will employ them in the right case. In this way, a higher standard of physiotherapy will be established in South Africa than exists in any other country in the world today, and many patients who, yesterday, could not be helped will be afforded relief today by precise manual measures.

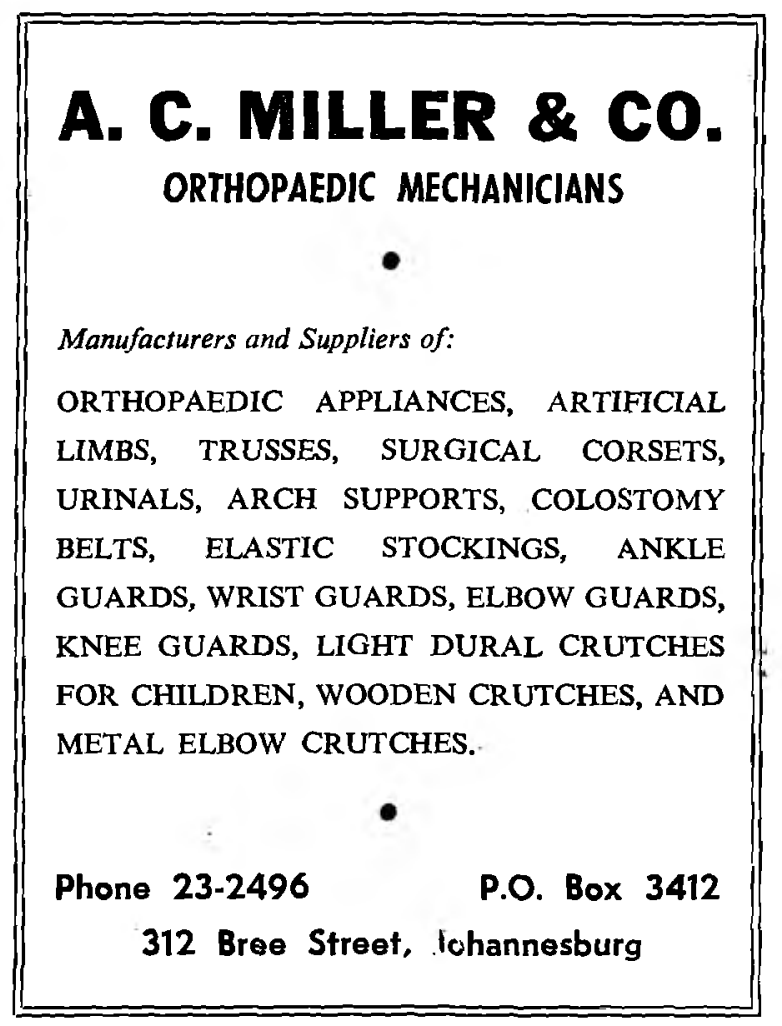

\section{G E N E R A L}

\section{FIRST NON-EUROPEAN PHYSIOTHERAPY SCHOOL}

On 4th May, 1964, history was made in Durban when the first non-European physiotherapy school was opened. The School is attached to the King Edward VIII Hospital. It was decided to commence with 12 students, six male and six female. There was considerable competition for the available places. A good pass in the matriculation examination with a high standard in Mathematics and English was required.

The course is of three years' duration and the students will study for the National Diploma in Physiotherapy of the Department of Education, Arts and Science. The school is in charge of Dr. Alexander and Dr. B. V. Schulze and Miss G. H. Jones, M.C.S.P. will be the Principal. She was viceprincipal of the Middlesex Hospital, London, Physiotherapy School for the past 10 years. Miss Heather Godfrey will assist with the teaching.

The official opening by Mr. E. C. Wilks, M.E.C. was on $23 \mathrm{rd}$ June, and was attended by members of the Natal Provincial Council.

This project had been under consideration for at least 12 years and it is very gratifying to see it actually in operation at last.

The South African Society of Physiotherapy wish Miss Jones and her Staff and Students every success in this great pioneering venture.

\section{S.A. FEDERATION OF BUSINESS AND PROFESSIONAL WOMEN}

The women members of the S.A.S.P. have been invited to become affiliated to the S.A. Federation of Business and Professional Women-an honour which your Society has gratefully accepted.

\section{COUNCIL FOR THE CARE OF THE AGED}

Mr. Rothberg, Miss A. Savin and Miss E. Botting will represent the S.A.S.P. at the Bi-Annual Conference of the above Council later this year. Miss Anne Savin has consented to speak at the Annual General Meeting of the Johannesburg Branch on 18th August, at Cottesloe.

\section{S.A. PARAPLEgic GaMES}

It was decided at a Central Executive meeting held in June to send a team of S.A. paraplegic athletes to the Games in Tokyo. A team from Rhodesia will accompany the South Africans. Some of these Springboks were seen in action at the Wanderers, Johannesburg, on Saturday, 15th August.

Births

To Mr. and Mrs. Klemp (nee Maureen Purvis) a son, Rory Charles on 20th March, 1964.

To Mr. and Mrs. McKean (nee Judy Gibbs), a son, Robert Sean on 29th February, 1964.

To Mr. and Mrs. Elmer Curry, a second daughter, Jennifer on 7th July, 1964.

To Professor and Mrs. K. Watson, a daughter in April. 